\title{
Acceptance determinants of 5G services
}

\section{Rana Saeed Al-Maroof ${ }^{\mathrm{a}}$, Iman Akour ${ }^{\mathrm{b}}$, Rose Aljanadac ${ }^{\mathrm{c}}$, Aseel M. Alfaisal ${ }^{\mathrm{c}}$ Raghad M. Alfaisal $^{\mathrm{d}}$, Ahmad Aburayya ${ }^{e}$ and Said A. Salloum ${ }^{\mathrm{f}, \mathrm{g}^{*}}$}

${ }^{a}$ English Language \& Linguistics, Al-Buraimi University College, Oman

${ }^{b}$ Information Systems Department, College of Computing \& Informatics, University of Sharjah, Sharjah, UAE

${ }^{c}$ Department of Languages and Translation, Northern Border University, KSA

${ }^{d}$ Faculty of Art, Computing and Creative Industries, Universiti Pendidikan Sultan Idris, Malaysia

${ }^{e}$ Doctor of Quality \& Operation Management, Quality \& Corporate Development Office, Dubai Health Authority, Dubai, UAE

${ }^{f}$ School of Science, Engineering, and Environment, University of Salford, UK

${ }^{g}$ Machine Learning and NLP Research Group, University of Sharjah, Sharjah, UAE

\section{CH R O N I C L E}

Article history:

Received: June 18, 202

Received in revised format: June

30, 2021

Accepted: August 12, 2021

Available online: August 12, 2021

Keywords:

$5 G$

Technology Acceptance Model

Perceived Enjoyment

Perceived Resources

Perceived Skills Readiness

\section{A B S T R A C T}

$5 \mathrm{G}$ is a revolutionary development in network technologies which is gradually becoming very common among people contributing significantly in different fields such as education, industry, agriculture, health, tourism and military. Currently, $5 \mathrm{G}$ is an outbreak change as opposed to the traditional service of the Internet since it offers better quality, ultra-fast connection, low-cost, reduced latency, energy saving, which makes its great impact even greater in people's life. The present study examines various factors that have a significant impact on the Use of 5G in the Gulf area. The study extended the TAM (Technology Acceptance Model) to include factors such as Perceived Enjoyment, Perceived Resources and Perceived Skills Readiness. The present research has adopted a hybrid model that incorporates TAM determinants with other external factors which have a direct relation with $5 \mathrm{G}$ as internet service. Previous studies have focused on the importance of $5 \mathrm{G}$ in different environments and countries. However, this study focuses on the newly spread Use of $5 \mathrm{G}$ in the gulf area by adopting a hybrid conceptual model. The findings suggest that $5 \mathrm{G}$ may help in promoting the usage of internet service more effectively with its low-cost, faster data transfer and better quality. Moreover, the findings indicate a positive effect of the gender as a mediator between the variables: Perceived Skills Readiness, Perceived Ease of use, and Perceived Resources.

\section{Introduction}

$5 \mathrm{G}$ is an up-graded wireless network service that is distinguished by its high-speed as compared to 4G (Gao, 2021). 5G service allows internet users to move freely among a variety of applications, sites, and purposes. Universities and schools seem to enjoy the privilege of using $5 \mathrm{G}$ because it helps facilitate communication in live stream video, and sharing data among students and teachers. 5G offers a unique opportunity to develop both deep and distance learning within Virtual Reality and Augmented Reality. Both high speed and delay reduction make it possible to combine deep and distance education. This means that teachers and students face less problematic situations and get immediate reaction or assessment (Baratè, Haus, Ludovico, Pagani, \& Scarabottolo, 2019a; Liu, Li, \& Carlsson, 2010). Similarly, health-care systems seem to be affected significantly by $5 \mathrm{G}$ technologies because it helps developing more practical, low-cost and smart systems due to its fast data

* Corresponding author.

E-mail address: sssalloum@sharjah.ac.ae (S. A. Salloum)

(C) 2021 by the authors; licensee Growing Science, Canada. doi: $10.5267 /$ j.ijdns. 2021.8 .006 
transmission and reliability (Ahad et al., 2020; Kim, Kim, Park, Kim, \& Chang, 2020; Aburayya et al., 2020a,b; Taryam et al., 2020; Taryam et al., 2021). The positive effect of $5 \mathrm{G}$ seems to be part of the so-called smart tourism which is the best way to avoid the huge damage of COIVID-19 to tourism as it enables tourists to travel everywhere using virtual reality, including museums, art galleries and other tourists destination.5G has facilitated the adoption of the smart tourism industry that suits the pandemic situation (Balandina, Balandin, Koucheryavy, \& Mouromtsev, 2015; Al-Khayyal et al., 2020; Peng, Lou, Kadoch, \& Cheriet, 2020; Shao, Bai, Shu, \& Joppe, 2020). The wide Use of the entertaining sites during the pandemic has extended the benefits of $5 \mathrm{G}$. Users of famous applications such as YouTube, TikTok and Instagram have admitted that fast connection is one of the crucial factors that encourages them to Use the $5 \mathrm{G}$ technology, hence, they are ready to accept, adopt and Use content-creation applications. (Boehm, 2019; Han \& Zhang, 2020). A similar influential effect has been found in the military and agriculture domains where $5 \mathrm{G}$ brings about vibrant effects. Its vital influence stems from different factors including its high-speed, efficiency, security and low-latency. 5G in agriculture has supported the Use of both Virtual Reality and robots to dominate agricultural procedures (Bhardwaj, 2020; Meng, 2019; Tang et al., 2021).

Recent studies by (Han \& Zhang, 2020; Shao et al., 2020) have shown that acceptance of 5G is affected by TAM determinants such as PEOS, PU and PE which control the acceptance and adopting of technologies. (Han \& Zhang, 2020) have added other influential factors: Perceived Interactivity and Technological Enhancements as additional factors. TAM model has been used by many researchers to assess technology users' behavior, namely, Perceived Ease of Use and Perceived Usefulness. Following (F. D Davis, 1989), other researchers tend to modify the TAM model by adding influential factors that contribute significantly to users' attitude towards using technology. They include computer anxiety, self-efficacy, experience normative pressure and many other factors (Al-alak \& Alnawas, 2011; Liu et al., 2010; Mac Callum \& Jeffrey, 2014a). What sets this research apart from previous literature is the addition of essential factors that affect $5 \mathrm{G}$ acceptance and adoption in a direct manner. They include Perceived Skills Readiness, Perceived Enjoyment and Perceived Resources. In addition, the current paper pays attention to the role of gender difference in accepting 5G technology. The research conducted by (Cheryan, Plaut, Handron, \& Hudson, 2013) sheds light on the importance of gender differences which can deeply contribute to the acceptance of men and women to specific technology. Accordingly, this study intends to investigate how men and women may share different perspectives towards Perceived Ease of use, Perceived Usefulness and Perceived Enjoyment along with Perceived Resources. These factors may vary among gender and gender difference functions as a mediator among other factors. To the best of our knowledge, previous research has been conducted depending on the TAM model as the main conceptual model, but the current study attempts to investigate the acceptance of $5 \mathrm{G}$ in a hybrid conceptual model where gender functions as the mediator.

\section{Literature review}

5G technologies brought a wave of groundbreaking changes in how we Use the internet, smartphones, and applications. Everyday applications now used by millions of people such as Maps, content-creation applications (i.e. YouTube, Snapchat and Instagram) and online-streaming services were a novelty ten years ago. However, with the introduction of 5G technologies, all the aforementioned novelties will simply be dimmed when compared to the ultra-speed 5G-based technologies (Lee \& Kim, 2020).

\section{$2.15 G$ in Education}

$5 \mathrm{G}$ is the promised 5th generation wireless network that could hypothetically hit the $1 \mathrm{~GB}$ per 8 seconds transmission speed, which makes it ultra-fast compared to the currently used $4 \mathrm{G}$ network. (Gao, 2021) reports that the 5G network is viewed as "providing high data rates, reducing latency, saving energy, lower costs, increasing system capacity and large-scale connectivity". This revolutionary development in network technologies will undoubtedly optimize education by enhancing the ability of education systems to create, upload and download content faster. It will also help educators Use Augmented Reality and Virtual Reality more to enrich the learning experience and bring more meaning to content. Such technology-enriched education will help educational systems reserve their resources, increase effectiveness and offer students the opportunity to take charge of their own learning. (Lee \& Kim, 2020) point out different factors that impact the adoption of 5G in university-level education. These factors are the device used in the learning/ teaching process and its characteristics, the learning environment, what is learnt and taught in the process and cost. They argue that both cost and the learning environment play a major role in determining users' intentions towards using $5 \mathrm{G}$ in university-level education. The least effective factor is the device used in the learning/ teaching process. In a study conducted by (Huang et al., 2020) to judge whether it is possible to depend on 4G LTE technologies and 5G LTE technologies in education, findings emphasize that education can depend on both technologies for presentation of clear, almost high-quality educational pre-recorded and live-stream videos. Moreover, adopting 5G technologies in schools and universities will enable teachers and students to create high-quality videos simultaneously. According to (Li, 2021), simulated teaching can also benefit from the adoption of 5G, where students of English are provided with software that supplies them with clips and videos, and a web-based system through which students can Use what they learned in the software to respond in virtually-real dialogues. Such a combination of software and system will require a much faster, more dependable, and very secure internet connection to keep the simulation going, and this is exactly where $5 \mathrm{G}$ technologies fit in. 
Liu et al. (2010) state that $5 \mathrm{G}$ has the capability to offer education a unique chance to develop both deep learning and distance learning through enhancing the learning/ teaching environment and equipping it with more "Artificial Intelligence, Interaction Mechanism, Virtual Reality and Augmented Reality", all of which require a dependable connection. 5G technologies provide such reliability in the form of speed and delay reduction, and ultimately help create a new type of education that is more hybrid in nature, combining deep learning, distance education and online education. 5G is a set of promising technologies when it comes to music education. It provides an opportunity to improve the currently existing e-learning music education (Baratè, Haus, Ludovico, Pagani, \& Scarabottolo, 2019b) and limitless possibilities of using Virtual Reality and Augmented Reality to teach regular online courses or hold large-scale online concerts and operas, (Baratè, Haus, Ludovico, Pagani, Scarabottolo, et al., 2019). 5G technologies present a solution to a reoccurring problematic situation in music education. Teachers and students alike face difficulty synchronizing performances and getting immediate or even fast-enough reaction or assessment, especially in classes or events that take place in different locations (i.e. distance education environment, online events or online performance) during which the need for synchronized visual-auditory content is pressing. 5G technologies are highly regarded where infrastructure is considered, especially if compared to high-tech devices. However, one must understand the importance of a wide and comprehensive process of actually building the necessary infrastructure that $5 \mathrm{G}$ technologies require, (Baratè, Haus, Ludovico, Pagani, \& Scarabottolo, 2019b). Xu et al. (2019) pointed out that educational systems are now under much pressure to accommodate their online/ distance programs infrastructure to the rising demand. This in turn will add to the data traffic load on the network which requires an adequate solution in the form of 5G technologies adoption in their infrastructure. In a study conducted by (Akbari, Rezvani, Shahriari, Zúñiga, \& Pouladian, 2020) students' opinions are investigated regarding the level to which $5 \mathrm{G}$ technologies can be easily learnt, utilized and effortlessly used. It sets out to highlight that Perceived Usefulness indicates the degree of confidence on the behalf of students when using $5 \mathrm{G}$ technologies can enhance their performance and effectiveness in classes. Findings reveal both direct and indirect impacts of Perceived Ease of Use, Perceived Usefulness, Trust, and Concentration on the Intention to use 5G.

\section{$2.25 G$ in Healthcare}

Akbari et al. (2020) point out that 5G technologies will have a major role in building smart health-care systems that are both practical and less costly than traditional ones. Compared to $4 \mathrm{G}$ and its predecessors, $5 \mathrm{G}$ technologies wins the speed, data transmission, reliability and coverage competition. Moreover, (Kim et al., 2020) discuss the potential Use of 5G technologies in Pre-hospital Paramedics, where 5G- with its encouraging features such as speed, reliability and low-latency communication- can play a role in developing the medical services provided to patients before they are transported to hospitals. However, one cannot ignore the fact that no matter how 5G-based health-care systems can be viewed positively, they are still too good to be true. Patients' privacy, unsatisfactory evidence used to formulate and adopt policies of Use and the need to build an extensive infrastructure that covers remote areas before actually deploying systems are just a few of the concerns regarding the establishment of $5 \mathrm{G}$ - based health-care systems.

\section{$2.35 G$ in Tourism}

5G technologies have their undeniable charms in tourism. Hit hard by the COVID-19 pandemic, the industry had no other option but to improvise, hence the inverted framework: you don't have to go to places; places come to you. The increasing Use of Virtual Reality in tourism, whether in virtual visits to museums, art galleries, historic sites or typical tourist-destinations like beaches and mountains, has made the need for quick adoption of $5 \mathrm{G}$ technologies in the industry urgent. Nonetheless, as Shao et al. (2020) state that potential tourists' (technically end-users) adoption of Virtual Reality enhanced by 5G technologies is affected by many factors. These are Perceived Usefulness, Perceived Ease of Use, Perceived Cost, Perceived Enjoyment and Perceived Immersion. E-tourism or "smart tourism" as coined by (Peng et al., 2020), which is presented as "green, ethical and clean tourism" by the World Tourism Organization (Balandina et al., 2015), is an emerging field that will possibly be where $5 \mathrm{G}$ technologies are best implemented. Smart tourism is the solution to many challenges faced by a huge number of tourists; unsafe destinations, getting robbed or scammed, the lack of Resources in some touristic destinations and of course the cost of travelling, obtaining a visa and booking accommodations. The development of 5G-based smart tourism can hugely benefit from combining Augmented Reality, Virtual Reality, Artificial Intelligence and Social Sharing with 5G shining features; speed, low-latency and coverage.

\section{$2.45 G$ in Military}

Unsurprisingly, 5G technologies have already been considered vital in the military for communications and strategies. With its undeniable advantages (speed, low-latency, efficiency and security) army strategists will rely more and more on these technologies to minimize the danger in field operations and casualties through the extensive Use of live-streaming and sharing with troops in different locations. The performance of non-human players in the field (drones, robots, sensors, cameras, autonomous vehicles) can also be enhanced and consequently providing fast feedback to soldiers in the field and shortening reaction time from operation-rooms, (Bhardwaj, 2020). 


\subsection{5 in Agriculture}

As in all other industries and aspects of life, agriculture can make considerable Use of a 5G-based farming system. Meng (2019) states that at the heart of this process is "adoption and automation"; the adoption of technologies and the automation of farming activities. Tang et al. (2021) discuss 5G implementations in farming. Drones can be used to enhance land productivity and make better choices on how to deal with crop cycles while requiring less time. In addition to drones, temperature, humidity and rain can be accurately detected by using internet-connected sensors which send ongoing reports to a 5G-based farming system to make quick decisions. This 5G-based farming system provides farmers with the opportunity to discuss whatever problems they face and book appointments with experts using Virtual Reality. Moreover, Augmented Reality can provide the system with continuous updates on the status of crops and detect pests and diseases. 5G-based farming systems can also optimize the Use of robots in fields to perform many farming activities such as planting, watering, taking care of animals, harvesting, and picking.

\section{$2.65 G$ in Entertainment}

Entertainment is perhaps where 5G technologies will be best appreciated, this includes gaming, video streaming, cloud computing and content creation by independent users using YouTube, Tik Tok and Instagram. Boehm (2019) explains that to better understand what $5 \mathrm{G}$ technologies in entertainment are capable of, one only needs to consider how gaming in the $4 \mathrm{G}$ era is viewed. Gaming is mostly done either using consoles (such as PlayStation ${ }^{\circledR}$ or Xbox ${ }^{\circledR}$ ) or via smartphones. However, smartphone gaming is not as fast or satisfying as console gaming because they essentially differ in the speed of the connection. In $5 \mathrm{G}$ gaming, gamers can enjoy the quality of an HD video while playing console-less games using any smart device and saving their accounts and content to servers. Han and Zhang (2020) express the need to study how users accept, adopt and Use content-creation applications. They conducted a study on how Tik Tok potential users' intentions towards the application using TAM. Results show that Perceived Ease of Use, Perceived Usefulness, Perceived Enjoyment and Perceived Interactivity all play an important role in determining users' intentions. However, technological enhancements in 5G-based content-creation applications sound the alarm about a possible breach of users' privacy.

\section{Hypotheses Development and the Conceptual Model}

\subsection{Perceived Skill Readiness (PSR)}

Perceived Skills Readiness usually refers to users' perception of their own ability to Use technology and specifically to use mobiles (Akour, 2010). It has a close relation with users' perception of effort-free technology which in turn contributes to motivation. Accordingly, when users feel that they have the required Skills to use a service or device, they are more willing to get involved and they engage better in the service (Odiakaosa \& Jere, 2017; Al-Khayyal et al., 2020). In a study by (Mutono \& Dagada, 2016) which examines the learner's perception of Skills Readiness, students reported that when they feel that technology is free of effort, they feel less anxious and the level of frustration becomes much lower. Accordingly, they feel that technology is more useful and easier to use. Hence the following hypothesis is proposed:

\section{H1: Perceived Ease of Use has a positive impact on intention to Use $5 G$.}

\subsection{TAM Model}

The TAM model was originally developed to account for the Perceived Usefulness and Perceived Ease of Use as core determinants of attitude towards behavioral intention (Fred D Davis, 1989). This implies that users' intention to use technology is highly affected by their attitudes on Ease of Use and Usefulness. Following (Fred D Davis, 1989), other researchers attempted to add other crucial issues such as computer anxiety, motivation, normative pressure, experience, digital literacy, self-efficacy, etc. to widen the scope of TAM. It is considered an attempt to include crucial elements that interact smoothly with Perceived Ease of Use and Perceived Usefulness (Al-alak \& Alnawas, 2011; Lu, Shi, Wang, Cao, \& Cui, 2010; Mac Callum \& Jeffrey, 2014b). Based on the previous assumption, it can be hypothesized that:

$\mathbf{H}_{2}:$ Perceived Usefulness has a positive impact on intention to Use $5 G$.
$\mathbf{H}_{3}:$ Perceived Ease of Use has a positive impact on intention to Use $5 G$.

\subsection{Perceived Enjoyment (PEN)}

Users of technology may react differently as far as their intention to use technology is concerned. Perceived Enjoyment is one of the natural reactions that may contribute to technology acceptance. Enjoyment refers to the level of engagement that users may have towards technology leading to a feeling of happiness and involvement. Enjoyment in using technology is influenced by the Perceived Pleasure during the real experience (Ahmad, Jameel, \& Raewf, 2021; Hsu \& Lin, 2008; Kankanhalli, Tan, \& Wei, 2005). Previous studies assess the Perceived Enjoyment differently. A study in Saudi Arabia has shown that the factor of Perceived Enjoyment is not evident in a group of undergraduate students. They assume that Perceived Enjoyment has a non-significant impact on users (Eid \& Al-Jabri, 2016). This stands in contrast with other previous studies in Malaysia. One 
study by (Moghavvemi, Sharabati, Paramanathan, \& Rahin, 2017) examines the effect of Perceived Enjoyment among a group of undergraduate students points out that Perceived Enjoyment is a significant and influential factor that support students' willingness and readiness to continue using the technology. Hence, Perceived Enjoyment has a positive and significant impact that contributes importantly to technology acceptance (Kanaan \& Gharibeh, 2013; Rahab \& Wahyuni, 2013). Accordingly, it is hypothesized that:

\section{$\mathbf{H}_{4}$ : Perceived Enjoyment has a positive impact on intention to Use $5 G$.}

\subsection{Perceived Resources (PR)}

Perceived Resources as a concept refers to the users' perception towards the organizational and technical infrastructure, that is; whether the existing infrastructure can really support the system or not. It is an attribute that has a close relation with the hardware, software, data and documentation. Perceived Resources as an external factor has been shown to affect both Perceived Ease of Use and Perceived Usefulness (Ku, 2009; Venkatesh, Morris, Davis, \& Davis, 2003; Xu et al., 2019). A study by (Mtebe \& Raisamo, 2014) has shown that the availability of resources has a vital impact on the intention to use the technology. In other words, Perceived Resources predicts the users' intention and facilitates the acceptance of the technology. A similar study by $(\mathrm{Ku}, 2009)$ has investigated the effect of Perceived Readiness in technology acceptance. They state that Perceived Resources has a close relation with TAM main constructs, namely, Perceived Ease of Use and Perceived Usefulness. The previous assumption leads to the following hypothesis:

\section{H5: Perceived Resources have positive effects on intention to Use $5 G$.}

\subsection{Differences as Mediator (GENDER)}

Gender Difference has been accounted for as an influential and important factor in users' intention to use and accept technology. Many researchers have given various explanations for Gender Differences in the field of technology. According to (Cheryan et al., 2013), gender differences are highly affected by the cultural environment which contributes directly to technology acceptance. Researchers have offered different results concerning the effect of Gender Differences on technology acceptance. A study by (Hatlevik \& Christophersen, 2013) has shown that there is no difference between male and female students in technology acceptance. Similar results have been obtained by (Hosein, Ramanau, \& Jones, 2010; Ihme \& Senkbeil, 2017) who reports that Gender Differences plays a small role in technology acceptance. On the other hand, other studies have reached the conclusion that Gender Difference plays a significant role in technology acceptance. Gender interest, stereotype and experience play a decisive role in creating significant differences among men and women (Ellemers, 2018; Fischer, Rohm, Gnambs, \& Carstensen, 2016). In a study by (Gnambs, 2021), women are more interested in accepting technology which helps in forming deeper experience and greater willingness. Accordingly, the following hypotheses can be formed:

M1: Gender Difference mediates the effect of PSR on intention to Use $5 G$.

$\mathbf{M}_{2}$ : Gender Difference mediates the effect of PU on intention to Use $5 G$.

$\mathbf{M}_{3}$ : Gender Difference mediates the effect of PEOU on intention to Use $5 G$.

$\mathbf{M}_{4}$ : Gender Difference mediates the effect of PEN on intention to Use $5 G$.

M5: Gender Difference mediates the effect of PR on intention to Use $5 G$.

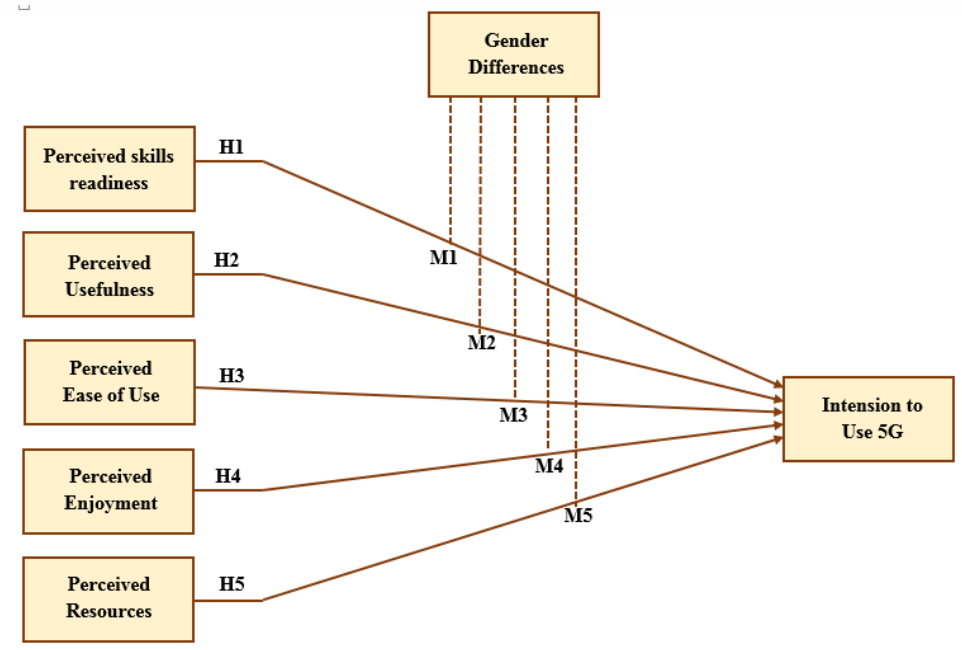

Fig. 1. Research Model 


\section{Research Methodology}

\subsection{Data collection}

Data was collected from 15 February 2021 till 31 March-2021 during the winter semester 2020/2021 by taking online surveys to the Gulf students. The study team circulated 600 questionnaires at random, and respondents submitted 576 of questionnaires, yielding a response rate of 96 percent. 24 of the completed questionnaires were rejected due to missing values. As a result, the researchers kept 576 questionnaires which were filled out and useful. As per (Krejcie \& Morgan, 1970) a total of 576 eligible responses were obtained with an acceptable data set range, for example, the expected sample size for a population comprising 1500 is 306 respondents. A sample size of 576 is much larger than inconsequential criteria. As a result, the structural equation modelling evaluation is suitable as a sample size (Chuan \& Penyelidikan, 2006), which was then used to validate the hypotheses. Also, notably, hypotheses were developed based on present theories while also being tailored to the Internet environment. To analyze the measurement model, the analysts used structural equation modelling (SEM) (SmartPLS Version 3.2.7). For a highly developed therapy, the final path model likewise can be utilized.

\subsection{Students' personal information / Demographic Data}

The assessment of the personal/ demographic data is summarized in Table 1. Male students made up 46 percent of the total, while female students made up 54 percent. Students' age was determined to be between 18 and 29 years for 47 percent of the respondents, and 53 percent were older than 29 years. Almost all of the respondents were university degree holders and came from educated families. In the light of the findings, 56 percent of respondents held a bachelor's degree, while $32 \%$ held a master's degree, and 12\% held a PhD degree. The "purposive sampling approach" was used as the exposure to the respondents was accessible and many were able to volunteer, as per (Al-Emran \& Salloum, 2017; Al Kurdi, Alshurideh, \& Salloum, 2020; Alghizzawi et al., 2018; M. Alshurideh, 2018; Habes, Salloum, Alghizzawi, \& Mhamdi, 2020; Al Kurdi et al., 2021; Salloum et al., 2021). This research sample consisted of students from various colleges; these students ranged in age and were enrolled in various programs at various levels. Furthermore, IBM SPSS Statistics version 23 was used to analyze the demographic data. Table 1 shows the respondents' complete demographic data.

Table 1

Demographic data of the respondents

\begin{tabular}{|c|c|c|c|}
\hline & Factor & Frequency & Percentage \\
\hline \multirow[t]{2}{*}{ Gender } & Female & 310 & $54 \%$ \\
\hline & Male & 266 & $46 \%$ \\
\hline \multirow[t]{4}{*}{ Age } & Between 18 to 29 & 269 & $47 \%$ \\
\hline & Between 30 to 39 & 133 & $23 \%$ \\
\hline & Between 40 to 49 & 93 & $16 \%$ \\
\hline & Between 50 to 59 & 81 & $14 \%$ \\
\hline \multirow[t]{3}{*}{ Education Qualification } & Bachelor & 322 & $56 \%$ \\
\hline & Master & 186 & $32 \%$ \\
\hline & Doctorate & 68 & $12 \%$ \\
\hline
\end{tabular}

\subsection{Study Instrument}

This study established a survey instrument to validate the hypothesis. The survey included 23 items in order to measure the eleven constructs in the questionnaire. Table 2 contains the sources for these constructs. The analysts modified and altered the questions from previous research to improve the study's efficacy.

Table 2

Constructs and their sources

\begin{tabular}{lcl}
\hline \multicolumn{1}{c}{ Constructs } & Number of items & \multicolumn{1}{c}{ Source } \\
\hline GENDER & 5 & (Gefen \& Straub, 1997; Morris \& Venkatesh, 2000) \\
INT & 3 & (Park, 2009) \\
PSR & 3 & (Akour, 2010) \\
PEOU & 3 & (Fred D Davis, Bagozzi, \& Warshaw, 1989) \\
PU & 3 & (Fred D Davis et al., 1989) \\
PEN & 3 & (Y. Huang, 2014) \\
PR & 3 & (Venkatesh et al., 2003) \\
\hline
\end{tabular}

Note: GENDER, gender differences; INT, intention to Use 5G; PSR, Perceived Skills Readiness; PEOU, Perceived Ease of use; PU, Perceived Usefulness; PEN, Perceived Enjoyment; PR, Perceived Resources.

\subsection{A pilot study of the questionnaire}

A pilot study was used to assess the questionnaire items' reliability. This pilot study included nearly 50 students who were chosen at random from a predetermined population. The sample size was determined with (600 students) predicated on $10 \%$ 
of the total sample size of this research, and the research guidelines were closely accompanied in this respect. Cronbach's alpha test was employed for internal reliability with IBM SPSS Statistics ver. 23 to assess the results of the pilot study, and satisfactory interpretations for the measurement items were depicted as an outcome. while we focus on the discussed pattern of social science research studies, a reliability coefficient of 0.70 is supposed to be acceptable (Jum C Nunnally \& Bernstein, 1978). Table 3 shows the Cronbach alpha readings for the given 7 measurement scales.

\section{Table 3}

Cronbach's Alpha values for the pilot study (Cronbach's Alpha $\geq 0.70$ ).

\begin{tabular}{|c|c|}
\hline Constructs & Cronbach's Alpha \\
\hline GENDER & 0.829 \\
\hline INT & 0.850 \\
\hline PSR & 0.892 \\
\hline PEOU & 0.875 \\
\hline PU & 0.858 \\
\hline PEN & 0.823 \\
\hline PR & 0.829 \\
\hline
\end{tabular}

Note: GENDER, gender differences; INT, intention to Use 5G; PSR, Perceived Skills Readiness; PEOU, Perceived Ease of use; PU, Perceived Usefulness; PEN, Perceived Enjoyment; PR, Perceived resources.

\subsection{Survey Structure}

The questionnaire survey was distributed by the analysts. The students in the United Arab Emirates (UAE) universities $(\mathrm{N}=600)$ provided online surveys, and this research will focus on two different universities. University of Fujairah and The British University in Dubai (BUiD) are two of the most well-known universities of UAE considered in this analysis.

A questionnaire survey was given to the students (Al-Emran \& Salloum, 2017). This survey was divided into three parts.

- The first section emphasizes the respondents' personal data.

- $\quad$ The second section presents eighteen items which highlight the basic questions about 5G systems.

- The third section includes five items that demonstrate Gender Differences effect.

The (23 items) are assessed using a five-point Likert scale, which includes the following scales: Strongly Disagree (1), Disagree (2), Neutral (3), Agree (4), and Strongly Agree (5).

five points: strongly disagree (1), disagree (2), neutral (3), agree (4), and strongly agreed (5).

\section{Findings and Discussion}

\subsection{Data Analysis}

The partial least squares-structural equation modeling (PLS-SEM) was used for the data analysis for the research (A. Ahmad \& Hamadneh, n.d.; R. Al-Maroof et al., 2021; R. S. Al-Maroof, Alhumaid, Alhamad, Aburayya, \& Salloum, 2021; Alaali et al., 2021; Capuyan et al., 2021; Makki et al., 2020; Mouzaek et al., 2021; Ringle, Wende, \& Becker, 2015; Ahmad et al., 2021) with the assistance of SmartPLS V.3.2.7 software. The collected data was analyzed using a two-step assessment approach that consist of a structural model and a measurement model (Hair, Hollingsworth, Randolph, \& Chong, 2017). PLSSEM was chosen for this study for a myriad of purposes. First and foremost, PLS-SEM is thought to be the best option when the goal of the study is to develop a present theory (Urbach \& Ahlemann, 2010). Second, the PLS-SEM (Hair Jr, Hult, Ringle, \& Sarstedt, 2016) can be used to effectively manage explorative experiments with complex models. Third, rather than separating the model into fragments, PLS-SEM analyzes the entire model as a single unit (Goodhue, Lewis, \& Thompson, 2012). PLS-SEM, produces accurate calculations sequentially, and enables concurrent analysis for both measurement and structural model (Barclay, Higgins, \& Thompson, 1995).

\subsection{Convergent validity}

Hair et al. (2017) suggest that construct reliability (such as composite reliability (CR), Dijkstra-Henseler's (PA), and Cronbach's alpha (CA)) and validity (along with convergent and discriminant validity) are included when evaluating the measurement model. Cronbach's alpha (CA) values from 0.728 to 0.878 are used to calculate construct reliability, as shown in Table 4. These numbers are greater than the threshold value of 0.7 (J. C. Nunnally \& Bernstein, 1994). According to Table 4 , the composite reliability (CR) values lie between 0.763 to 0.897 , which are significantly higher than the recommended value of 0.7 (Kline, 2015). Instead, researchers can use the Dijkstra-Henseler's rho (pA) reliability coefficient to assess and document construct reliability. The reliability coefficient $\rho$ A, like CA and CR, should have values of 0.70 or greater in experimental studies and ranges of 0.80 or 0.90 in more proceeded analysis levels (Hair, Ringle, \& Sarstedt, 2011; Henseler, Ringle, $\&$ Sinkovics, 2009; Nunnally \& Bernstein, 1994). The reliability coefficient $\rho$ A of each measurement construct is greater than 0.70 , as seen in Table 4 . With these findings, construct reliability was verified, and all constructs were considered adequate without any error at the conclusion. 
For the measurement of convergent validity, the average variance extracted (AVE) and factor loading must be checked (J. Hair et al., 2017). The proposed value of 0.7 held lower than the values of all factor loadings, as per Table 4 . In particular, the AVE yielded values between 0.533 and 0.756 that are greater than the recommended of ' 0.5 ', as shown in Table 1 . Depending on the upcoming findings, convergent validity can be finally accomplished for all constructs.

\subsection{Discriminant validity}

Again, for measurement of discriminant validity, the following parameters were proposed to be measured first: the FornellLarker criterion and the Heterotrait-Monotrait ratio (HTMT) (Fornell \& Larcker, 1981). The Fornell-Larker condition supports the criteria, as all AVEs and their square roots are higher than their correlation against other constructs (Henseler, Ringle, \& Sarstedt, 2015), as per the results of Table 5. Table 6 displays the HTMT ratio findings which show that the threshold value of 0.85 remains higher than the value of each construct (Henseler et al., 2015). As a result, the HTMT ratio is determined. These findings are used to assess discriminant validity. According to the findings of the study, there were no problems with the assessment measurement model's validity and reliability. As a result, the structural model can be assessed using the collected data.

\section{Table 4}

Convergent validity results which assure acceptable values (Factor loading, Cronbach's Alpha, composite reliability, Dijkstra-Henseler's rho $\geq 0.70 \&$ AVE $>0.5$ )

\begin{tabular}{|c|c|c|c|c|c|c|}
\hline Constructs & Items & $\begin{array}{c}\text { Factor } \\
\text { Loading }\end{array}$ & Cronbach's Alpha & CR & PA & AVE \\
\hline \multirow[t]{5}{*}{ Gender Difference } & GENDER1 & 0.857 & \multirow[t]{5}{*}{0.878} & \multirow[t]{5}{*}{0.888} & \multirow[t]{5}{*}{0.842} & \multirow[t]{5}{*}{0.756} \\
\hline & GENDER2 & 0.851 & & & & \\
\hline & GENDER3 & 0.853 & & & & \\
\hline & GENDER4 & 0.868 & & & & \\
\hline & GENDER5 & 0.862 & & & & \\
\hline \multirow[t]{3}{*}{ Intention to Use $5 \mathrm{G}$} & INT1 & 0.803 & \multirow[t]{3}{*}{0.799} & \multirow[t]{3}{*}{0.882} & \multirow[t]{3}{*}{0.799} & \multirow[t]{3}{*}{0.714} \\
\hline & INT2 & 0.869 & & & & \\
\hline & INT3 & 0.862 & & & & \\
\hline \multirow[t]{3}{*}{ Perceived Skills Readiness } & PSR1 & 0.777 & \multirow[t]{3}{*}{0.767} & \multirow[t]{3}{*}{0.897} & \multirow[t]{3}{*}{0.828} & \multirow[t]{3}{*}{0.743} \\
\hline & PSR2 & 0.855 & & & & \\
\hline & PSR3 & 0.841 & & & & \\
\hline \multirow[t]{3}{*}{ Perceived Ease of use } & PEOU1 & 0.865 & \multirow[t]{3}{*}{0.827} & \multirow[t]{3}{*}{0.847} & \multirow[t]{3}{*}{0.729} & \multirow[t]{3}{*}{0.649} \\
\hline & PEOU2 & 0.861 & & & & \\
\hline & PEOU3 & 0.860 & & & & \\
\hline \multirow[t]{3}{*}{ Perceived Usefulness } & PU1 & 0.845 & \multirow[t]{3}{*}{0.868} & \multirow[t]{3}{*}{0.860} & \multirow[t]{3}{*}{0.782} & \multirow[t]{3}{*}{0.687} \\
\hline & PU2 & 0.853 & & & & \\
\hline & PU3 & 0.825 & & & & \\
\hline \multirow[t]{3}{*}{ Perceived Enjoyment } & PEN1 & 0.768 & \multirow[t]{3}{*}{0.728} & \multirow[t]{3}{*}{0.763} & \multirow[t]{3}{*}{0.765} & \multirow[t]{3}{*}{0.533} \\
\hline & PEN2 & 0.830 & & & & \\
\hline & PEN3 & 0.817 & & & & \\
\hline \multirow[t]{3}{*}{ Perceived Resources } & PR1 & 0.782 & \multirow[t]{3}{*}{0.772} & \multirow[t]{3}{*}{0.865} & \multirow[t]{3}{*}{0.780} & 0.681 \\
\hline & PR2 & 0.870 & & & & \\
\hline & PR3 & 0.833 & & & & \\
\hline
\end{tabular}

Table 5

Fornell-Larcker Scale

\begin{tabular}{|c|c|c|c|c|c|c|c|}
\hline & GENDER & INT & PSR & PEOU & $\mathbf{P U}$ & PEN & PR \\
\hline GENDER & 0.833 & & & & & & \\
\hline INT & 0.545 & 0.862 & & & & & \\
\hline PSR & 0.455 & 0.562 & 0.869 & & & & \\
\hline PEOU & 0.574 & 0.507 & 0.805 & 0.808 & & & \\
\hline PU & 0.408 & 0.516 & 0.474 & 0.529 & 0.875 & & \\
\hline PEN & 0.527 & 0.432 & 0.520 & 0.570 & 0.430 & 0.882 & \\
\hline PR & 0.506 & 0.377 & 0.540 & 0.591 & 0.427 & 0.525 & 0.806 \\
\hline
\end{tabular}

Note: GENDER, gender differences; INT, intention to Use 5G; PSR, Perceived Skills Readiness; PEOU, Perceived Ease of use; PU, Perceived Usefulness; PEN, Perceived Enjoyment; PR, Perceived Resources.

Table 6

Heterotrait-Monotrait Ratio (HTMT)

\begin{tabular}{|c|c|c|c|c|c|c|c|}
\hline & GENDER & INT & PSR & PEOU & $\mathbf{P U}$ & PEN & PR \\
\hline \multicolumn{8}{|c|}{ GENDER } \\
\hline INT & 0.229 & & & & & & \\
\hline PSR & 0.383 & 0.310 & & & & & \\
\hline PEOU & 0.498 & 0.392 & 0.299 & & & & \\
\hline PU & 0.564 & 0.229 & 0.678 & 0.367 & & & \\
\hline PEN & 0.666 & 0.441 & 0.610 & 0.455 & 0.222 & & \\
\hline PR & 0.597 & 0.395 & 0.507 & 0.410 & 0.425 & 0.397 & \\
\hline
\end{tabular}

Note: GENDER, gender differences; INT, intentionto Use 5G; PSR, Perceived Skills Readiness; PEOU, Perceived Ease of use; PU, Perceived Usefulness; PEN, Perceived Enjoyment; PR, Perceived resources. 


\subsection{Model fit}

The corresponding fit measures are available via SmartPLS: The model fit in PLS-SEM is implied by the standard root mean square residual (SRMR), exact fit criteria, d ULS, d G, Chi-Square, NFI, and RMS theta. The SRMR represents the discrepancy between observed and model inferred correlations (Trial, n.d.), with values just under 0.08 regarded as good model fit measures (Hair, J., Hult, G. T. M., Ringle, C., Sarstedt, M., Hair, J. F. F., Hult, G. T. M., ... Sarstedt, 2016). Good Model fit is suggested by NFI values greater than 0.90 (Hu \& Bentler, 1998). The NFI is a ratio of the proposed model's Chi2 value to the null or benchmark model (Lohmöller, 1989). NPI is not suggested as a model fit measure because the larger the parameters, the greater the NFI (Hair, J., Hult, G. T. M., Ringle, C., Sarstedt, M., Hair, J. F. F., Hult, G. T. M., ... Sarstedt, 2016). The squared Euclidean distance, d ULS, and the geodesic distance, d G, are two metrics that show a discrepancy between empirical and composite factor model covariance matrices (Dijkstra \& Henseler, 2015; Hair, J., Hult, G. T. M., Ringle, C., Sarstedt, M., Hair, J. F. F., Hult, G. T. M., ... Sarstedt, 2016). RMS theta assesses the degree of outer model residuals correlation and is only relevant to reflective models (Lohmöller, 1989). The improved the PLS-SEM model, the nearer the RMS theta value is to zero, and values below 0.12 are taken as a good fit, while everything else indicates a lack of fit (Henseler et al., 2014). The saturated model, according to (Hair Jr et al., 2016), determines correlation between all constructs, while the estimated model considers total effects and model structure. The PLS-SEM model's goodness-of-fit was significant to even show global PLS model validity, as 0.068 reading of the RMS_theta suggesting in Table 7.

Table 7

Model fit indicators

\begin{tabular}{lcc}
\hline & & Complete Model \\
\cline { 2 - 3 } & Saturated Model & Estimated Mod \\
\hline SRMR & 0.047 & 0.047 \\
d_ULS & 0.797 & 0.797 \\
d_G & 0.496 & 0.496 \\
Chi-Square & 479.657 & 479.669 \\
NFI & 0.864 & 0.864 \\
Rms Theta & & 0.068 \\
\hline
\end{tabular}

\subsection{Hypotheses testing using PLS-SEM}

The structural equation model was used in conjunction with Smart PLS consist of maximum likelihood estimation to determine the interdependence of number of theoretical constructs of structural model (Al-Emran, Arpaci, \& Salloum, 2020; S. A. Salloum, Al-Emran, Abdallah, \& Shaalan, 2017; S.A. Salloum, Al-Emran, Abdallah, \& Shaalan, 2018; Said A Salloum, Alhamad, Al-Emran, Monem, \& Shaalan, 2019). The proposed hypotheses were examined in this method. The model has a moderate predictive power (Chin, 1998), as shown in Table 8, Fig 2 which means it can predict approximately 46 percent of the variance in Intention to Use $5 \mathrm{G}$. Table 9 shows the beta $(\beta)$ values, t-values, and $\mathrm{p}$-values for each one of the hypotheses formulated using the PLS-SEM method, depending on the results obtained. All the hypotheses were clearly supported by all of the researchers, except H4. The empirical data supported hypotheses H1, H2, H3, and H5 depend upon the analysis of the data, while $\mathrm{H} 4$ was rejected.

The first hypothesis examines the relationship between Perceived Skills Readiness (PSR) and Intention to Use 5G (INT) ( $\beta$ $=0.378, t=6.976)$. The result of this hypothesis reveals that Perceived Skills Readiness (PSR) has a significant positive impact on the Intention to Use 5G (INT). Thus, H1 is supported. The second hypothesis describes the correlation between Perceived Usefulness (PU) and Intention to Use $5 \mathrm{G}(\mathrm{INT})(\beta=0.182, \mathrm{t}=4.278)$. This hypothesis indicates that Perceived Usefulness (PU) has a significant positive effect on Intention to Use $5 \mathrm{G}$ (INT) Therefore, H2 is supported.

The third hypothesis indicates the relationship between Perceived Ease of Use (PEOU) and the Intention to Use 5G (INT) ( $\beta$ $=0.261, \mathrm{t}=5.6758)$. This hypothesis suggests that Perceived Ease of Use (PEOU) has a significant positive influence on the Intention to Use 5G. Hence, H3 is supported. The fourth hypothesis inspects the correlation between Perceived Enjoyment $(\mathrm{PEN})$ and the Intention to Use $5 \mathrm{G}(\beta=-0.019, \mathrm{t}=0.423)$. This hypothesis demonstrates that Perceived Enjoyment $(\mathrm{PEN})$ has a negative influence on the Intention to Use 5G. Thus, H4 is not supported. The fifth hypothesis reveals the correlation between Perceived Resources (PR) and the Intention to Use 5G (INT) $(\beta=0.111, t=2.760)$. This hypothesis points out that Perceived Resources (PR) has a significant positive effect on the Intention to Use 5G. Hence, H5 is supported.

There is a mediating impact when an additional variables is used to create a relation with the current variables and the additional variable. The mediator variable main function is to give a clear justification for the relationship that may exist between the original variable and the additional one. The newly created associations usually include a group of relationships with one more than one intervening construct creating the so-called indirect effects. Studies in this respect should investigate the mediating effects following the study by (Preacher \& Hayes, 2008) and bootstrapping the distribution of samples to build an indirect effect (Santos-Vijande, López-Sánchez, \& Rudd, 2016). This simply implies that simple and different mediator models bootstrapping should be created which is usually followed by Indirect Effects plus Confidence Interval Bias Corrected. In the this type of analysis, we search for the direct and indirect effects of Perceived Skills Readiness (PSR), Perceived Usefulness (PU), Perceived Ease of Use (PEOU), Perceived Enjoyment (PEN), and Perceived Resources (PR) on the Intention 
to Use 5G through Gender Differences (GENDER) (see Table 11 and Fig. 1). Empirically speaking, the data could substantiate the positively obtained effects illustrated in Figure 2. When the more complex cause-effect relationship is examined. We, therefore, combine the simple and the more complex cause-effect relationships models in a mediator model (Figure 2). In addition to M1, M2, M3, M4 we would need to establish hypothesis M5: The direct relationship between the Perceived Skills Readiness (PSR) and the Intention to Use 5G is mediated by Gender Differences (GENDER), and Perceived Usefulness (PU) affects the Intention to Use $5 \mathrm{G}$ mediated through Gender Differences (GENDER), and Perceived Ease of Use (PEOU) affects the Intention to Use 5G mediated through Gender Differences (GENDER), and Perceived Enjoyment (PEN) affects the Intention to Use $5 \mathrm{G}$ mediated through Gender Differences (GENDER), and Perceived Resources (PR) affects the Intention to Use 5G mediated through Gender Differences (GENDER). If we use the available data to empirically estimate the model, we will obtain the estimated relationships with the expected signs. When extending the model by the Perceived Skills Readiness (PSR), Perceived Usefulness (PU), Perceived Ease of Use (PEOU), Perceived Enjoyment (PEN), and Perceived Resources (PR) we obtain the "true" relationship between Perceived Skills Readiness (PSR), Perceived Usefulness (PU), Perceived Ease of Use (PEOU), Perceived Enjoyment (PEN), and Perceived Resources (PR) with the Intention to Use 5G through Gender Differences (GENDER) (M. T. Alshurideh, Al Kurdi, \& Salloum, 2021).

Moderating effect exercised by Gender over apparent Perceived Skills Readiness (PSR), Perceived Usefulness (PU), Perceived Ease of Use (PEOU), Perceived Enjoyment (PEN), and Perceived Resources (PR) of constructs was unfolded through additional testing. The effect of variables on direction or intensity of relationship among dependent and independent variables can be explained through the moderator effect. Table 11 depicts the outcomes of current analysis which show that excluding M2 and M4, all other hypotheses were accepted signifying that Perceived Usefulness (PU) and Perceived Enjoyment (PEN) of constructs' relationship is not affected by Gender. But, Perceived Skills Readiness (PSR), Perceived Ease of Use (PEOU), and Perceived Resources (PR) experienced a positive effect due to the relationship between PSR, PEOU, and PR and the aspect of GENDER whereby Gender was used as moderator.

Table 8

$\mathrm{R}^{2}$ of the endogenous latent variables

\begin{tabular}{lcc}
\hline \multicolumn{1}{c}{ Constructs } & $\mathbf{R}^{\mathbf{2}}$ & Results \\
\hline Intention to Use 5G & 0.456 & Moderate \\
\hline
\end{tabular}

Table 9

Hypotheses-testing of the research model (significant at $\mathrm{p}^{* *}<=0.01, \mathrm{p}^{*}<0.05$ )

\begin{tabular}{cccccc}
\hline H & Relationship & Path & $t$-value & $p$-value & Direction \\
\hline H1 & PSR-> INT & 0.378 & 6.976 & 0.000 & Positive \\
H2 & PU -> INT & 0.182 & 4.278 & 0.000 & Pupported** \\
H3 & PEOU-> INT & 0.261 & 5.675 & 0.000 & Supported** \\
H4 & PEN-> INT & -0.019 & 0.423 & 0.673 & Positive \\
H5 & PR-> INT & 0.111 & 2.760 & 0.006 & Negative \\
\hline
\end{tabular}

Note: INT, intention to Use 5G; PSR, Perceived Skills Readiness; PEOU, Perceived Ease of use; PU, Perceived Usefulness; PEN, Perceived Enjoyment; PR, Perceived Resources.

Table 10

Moderator Analysis Result

\begin{tabular}{|c|c|c|c|c|c|c|c|c|c|}
\hline \multirow[t]{2}{*}{$\mathbf{H}$} & \multirow[t]{2}{*}{ Relationship } & \multirow{2}{*}{$\begin{array}{c}\text { Path a } \\
\text { IV } \rightarrow \text { Me- } \\
\text { diator }\end{array}$} & \multirow{2}{*}{$\begin{array}{l}\text { Path b } \\
\text { Mediator } \\
\rightarrow \text { DV }\end{array}$} & \multirow[t]{2}{*}{$\begin{array}{c}\text { Indirect } \\
\text { Effect }\end{array}$} & \multirow{2}{*}{$\begin{array}{c}\text { SE } \\
\text { Standard } \\
\text { deviation }\end{array}$} & \multirow[t]{2}{*}{ t-value } & \multicolumn{2}{|c|}{$\begin{array}{c}\text { Bootstrapped Confidence } \\
\text { Interval }\end{array}$} & \multirow[t]{2}{*}{ Decision } \\
\hline & & & & & & & $95 \%$ LL & $95 \%$ UL & \\
\hline M1 & $\mathrm{PSR} \times$ GENDER $\rightarrow$ INT & 0.123 & 0.701 & 0.086 & 0.040 & 6.015 & 0.008 & 0.165 & Supported \\
\hline M2 & PU $\times$ GENDER $\rightarrow$ INT & 0.078 & 0.701 & 0.055 & 0.044 & 5.413 & -0.032 & 0.141 & Not supported \\
\hline M3 & $\mathrm{PEOU} \times$ GENDER $\rightarrow$ INT & 0.204 & 0.701 & 0.143 & 0.054 & 6.164 & 0.037 & 0.249 & Supported \\
\hline M4 & $\mathrm{PEN} \times \mathrm{GENDER} \rightarrow \mathrm{INT}$ & 0.110 & 0.701 & 0.077 & 0.043 & 6.164 & -0.007 & 0.161 & Not supported \\
\hline M5 & $\mathrm{PR} \times \mathrm{GENDER} \rightarrow \mathrm{INT}$ & 0.333 & 0.701 & 0.233 & 0.046 & 6.164 & 0.143 & 0.324 & Supported \\
\hline
\end{tabular}

Note: GENDER, gender differences; INT, intention to Use 5G; PSR, Perceived Skills Readiness; PEOU, Perceived Ease of use; PU, Perceived Usefulness; PEN, Perceived Enjoyment; PR, Perceived resources.

\section{Conclusion}

This study has reached significant results. Firstly, 5G is a type of service that is innovative, ultra-reliable with low latency communication. It can be used in association with new applications, and it enables new sources for its users. Due to its importance, the 5G mobile service has been recently introduced in many countries all over the world to facilitate the development and the inclusion of totally new services. $5 \mathrm{G}$ has added a lot to many fields as it adds to users' preferences and usage the ability to download faster and surf more and more applications and websites (Gidlund, Lennvall, \& Akerberg, 2017; Maeng, Kim, \& Shin, 2020; Minoli \& Occhiogrosso, 2019). The current study seems to be in line with results which are obtained from previous studies because it has proven that $5 \mathrm{G}$ is an innovative service invented to facilitate the usage of applications and website all over the world. The study concludes that the acceptance of $5 \mathrm{G}$ is massive due to its high speed and quick data transmission. 5G is highly accepted since users perceived it as easy, useful and competent with their skills. 


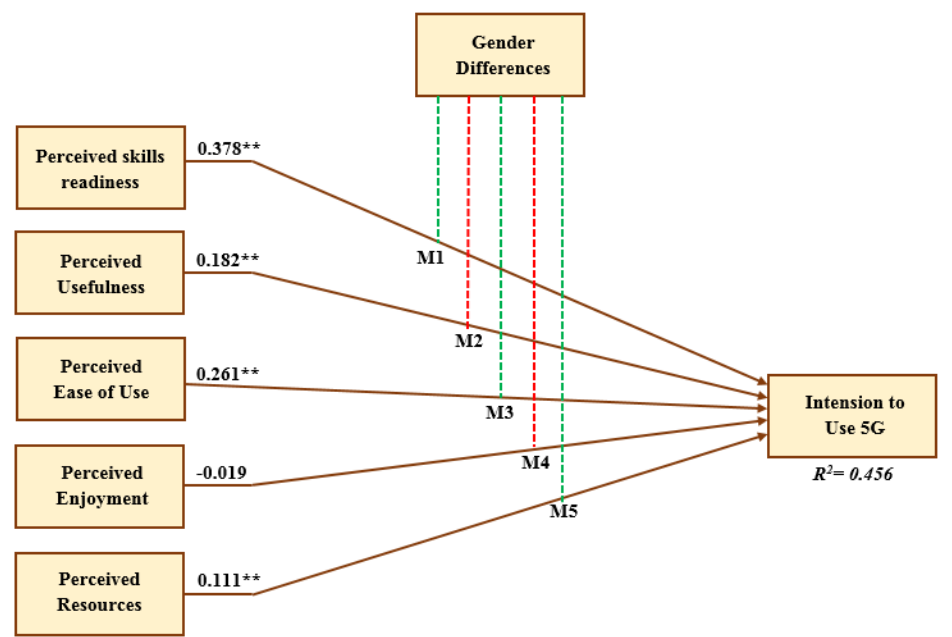

Fig. 2. Path coefficient of the model (significant at $\mathrm{p}^{* *}<=0.01, \mathrm{p}^{*}<0.05$ )

Secondly, the current study reaches the conclusion that both Perceived Ease of Use and Perceived Usefulness affect the acceptance of $5 \mathrm{G}$. This result is supported in the literature from two different perspectives. The first one is offered by (Neokosmidis et al., 2017) who state that 5G has to be supported as it is evaluated as desirable and preferred by many users. The high demand for the $5 \mathrm{G}$ service stems from the fact that it has a high priority of performance, high reliability, and fast data rate in addition to its high security and privacy. The second perspective is that users of $5 \mathrm{G}$, in the current study and in previous studies, have positively evaluated perceived usefulness and perceived ease of use as two main constructs in TAM. In a study by (Martin, Ragot, \& Savaux, 2021), they point out that users' perceived 5G as easy and useful which is supported by the present study. However, this study has shown that Perceived Enjoyment is not an effective variable when the 5G service is used. Perceived Enjoyment does not play any influential role in this respect. This stands in contrast with previous studies on the Perceived Enjoyment, where Enjoyment has proven to add extra value to the acceptance of technology (A. R. Ahmad et al., 2021; Hsu \& Lin, 2008; Kankanhalli et al., 2005). Furthermore, all these previous studies have shown that there is a connection between Perceived Enjoyment and Perceived Usefulness which is not evident in the present study.

Thirdly, Perceived Skills Readiness is an important variable in the acceptance of 5G. Perceived Skills Readiness which has a close relationship with users' ability to be competent in using technology is supported. This is consistent with studies by (Akour, 2010; Odiakaosa \& Jere, 2017) who state that users are more willing to use a device whenever they feel they are skillful enough. Similarly, the Perceived Resources are positively supported due to the availability of newly built infrastructure. The result of Perceived Resources is in agreement with studies by (Ku, 2009; Mtebe \& Raisamo, 2014) who sheds the light on the importance of Perceived Resources as a variable in accepting technology.

Finally, the mediator variable of Gender Difference seems to be effective in pinpointing the differences between males' and females' perceptions of 5G. The study has reached the conclusion that Gender moderates the effect of Perceived Ease of Use and Perceived Skills Readiness on the Intention to Use 5G. Similarly, the impact of Perceived Resources also moderates on behavioral intention towards $5 \mathrm{G}$. These results are in line with the findings obtained by previous studies where the differences between male and female contribute significantly (Ilie, Van Slyke, Green, \& Lou, 2005; Khodabandelou, Ab Jalil, Wan Ali, \& bin Mohd Daud, 2014; Warsame \& Ireri, 2018). On the other hand, the study has found out that Gender does not moderate the effect of Perceived Enjoyment and Perceived Usefulness. This implies that Gender as a moderator is not positively supported to moderate the relation between Perceived Enjoyment and Perceived Usefulness on the Intention to Use 5G. Similar findings are found in literature as previous studies have shown that Gender may not be an influential moderator to accept technology. In a study by (Faqih \& Jaradat, 2015), they examine the acceptance of e-payment and they reveal that Gender Differences has no impact on e-payment

\subsection{Empirical Implication of the Study}

Based on the discussed results, we offer some important implications. First, $5 \mathrm{G}$ provides its users with innovative service. Its innovativeness can be identified as being continuous easily updated (Maeng et al., 2020). 5G has technical and innovative features that can serve wider population in different field such as agriculture, tourism, education, and military. It can easily be part of our daily life, and will be a service that cannot be ignored by educators, students, researchers and others. Second, the fact that $5 \mathrm{G}$ has a high degree of flexibility entails that it will be common among users all over the world. The 'flexibility as a crucial factor is offered by (Neokosmidis et al., 2017) who sheds light on the high security and privacy of 5G which makes it more flexible and in high demand. Therefore, colleges, factories and public institutions should assist the spread of $5 \mathrm{G}$ as a flexible service to its users in addition to being well-trusted and private. 


\subsection{Managerial Implications of the Study}

From the managerial point of view, the following two implications are directed to practitioners. Firstly, practitioners have always assured us that $5 \mathrm{G}$ technology is a kind of innovation that will be part of users main interests and cannot be abandoned easily (Bauer \& Bohlin, 2018). Accordingly, practitioners should find ways to increase users' interest and desire to use the $5 \mathrm{G}$ service constantly by making it available in city centers , the suburbs as well as in remote areas. The availability of the service will facilitate the widespread of the $5 \mathrm{G}$ as a future service. Secondly, practitioners should pay attention to the influential role of 5G in Smart Cities. A study by (Minoli \& Occhiogrosso, 2019) has put more emphasis on 5G as an influential variable to facilitate the IoT in Smart Cities. Thus, the use of $4 \mathrm{G}$ can be useful for the near future in areas where there is less demand on technology. However, this fact stands in contrast with users' need in the coming future in Smart Cities, hence, practitioners should put into consideration the high demand of 5G in Smart City applications which usually need high bandwidth and wave frequencies. Thirdly, governments should take steady steps to encourage people all over the world to adopt $5 \mathrm{G}$ technology. Governments should also encourage challenging the spreading misconceptions of 5G and promote its unique and innovative features.

\subsection{Limitations of the Study and Future Work}

This study is limited in the sample population of the Gulf area. The questionnaire was distributed among users in the Gulf area to investigate users' acceptance of $5 \mathrm{G}$ in a limited place as compared with the spread of 5G all over the world. Furthermore, this study is limited to 5G as an innovative service and has not built any comparison between 5G and 4G. Accordingly, future studies can investigate the acceptance of $5 \mathrm{G}$ as compared to $4 \mathrm{G}$. Moreover, this study has focused on the Gender Difference as a mediation variable to examine how Gender may affect the adoption and acceptance of $5 \mathrm{G}$. Future studies may focus on Age as a moderator in 5G acceptance as it is well-known that teenagers' interest in technology is different from adults' and seniors' interest and desire to accept this service. Moreover, this study is limited to the following variables: Perceived Ease of use, Usefulness, Enjoyment, Resources and Skills Readiness. Future studies can investigate other important variables such as Security, Privacy, Perceived Risk and Trust as variables to measure the acceptance of 5G services. Finally, this study has time- limitation. Future studies can adopt a longitudinal approach to offer a comprehensive perspective and full understanding of user' perception of the $5 \mathrm{G}$ service.

\section{References}

Aburayya, A., Al Marzouqi, A., Al Ayadeh, I., Albqaeen, A., \& Mubarak, S. (2020a). Evolving A Hybrid Appointment System for Patient Scheduling in Primary Healthcare Centres in Dubai: Perceptions of Patients and Healthcare Provider. International Journal on Emerging Technologies, 11(2), 251-260.

Aburayya, A., Alshurideh, M., Al Marzouqi, A., Al Diabat, O., Alfarsi, A., Suson, R., Salloum, S. A., Alawadhi, D., \& Alzarouni, A. (2020b) Critical Success Factors Affecting the Implementation of TQM in Public Hospitals: A Case Study in UAE Hospitals. Systematic Reviews in Pharmacy, 11(10), 230-242.

Ahad, A., Tahir, M., Aman Sheikh, M., Ahmed, K. I., Mughees, A., \& Numani, A. (2020). Technologies trend towards 5G network for smart health-care using IoT: A review. Sensors, 20(14), 4047.

Ahmad, A. R., Jameel, A. S., \& Raewf, M. (2021). Impact of Social Networking and Technology on Knowledge Sharing among Undergraduate Students. International Business Education Journal, 14(1), 1-16.

Ahmad, A., Alshurideh, M., Al Kurdi, B., Aburayya, A., \& Hamadneh, S. (2021). Digital transformation metrics: a conceptual view. Journal of management Information and Decision Sciences, 24(7), 1-18.

Akbari, M., Rezvani, A., Shahriari, E., Zúñiga, M. A., \& Pouladian, H. (2020). Acceptance of 5 G technology: Mediation role of Trust and Concentration. Journal of Engineering and Technology Management, 57, 101585.

Akour, H. (2010). Determinants of mobile learning acceptance: an empirical investigation in higher education. Oklahoma State University.

Al Kurdi, B., Alshurideh, M., \& Salloum, S. A. (2020). Investigating a theoretical framework for e-learning technology acceptance. International Journal of Electrical and Computer Engineering (IJECE), 10(6), 6484-6496.

Al Kurdi, B., Alsurideh, M., Nuseir, M., Aburayya, A., \& Salloum, S.A. (2021). The effects of subjective norm on the intention to use social media networks: An exploratory study using PLS-SME and machine learning approach. In A. Hassanien \& K. Chang. Advanced Machine Learning Technologies and Applications, 324-334. Springer.

Alaali, N., Al Marzouqi, A., Albaqaeen, A., Dahabreh, F., Alshurideh, M., Mouzaek, E., Alrwashdh, S., Iyadeh, I., Salloum, S., \& Aburayya, A. (2021). The Impact of Adopting Corporate Governance Strategic Performance in the Tourism Sector: A Case Sudy in the kingdom of Bahrain. Journal of Legal, Ethical and Regulatory Issues, 24(1), 1-18.

Al-alak, B. A., \& Alnawas, I. A. M. (2011). Measuring the acceptance and adoption of e-learning by academic staff. Knowledge Management \& E-Learning, 3(2), 201.

Al-Emran, M., \& Salloum, S. A. (2017). Students' Attitudes Towards the Use of Mobile Technologies in e-Evaluation. International Journal of Interactive Mobile Technologies (IJIM), 11(5), 195-202.

Al-Emran, M., Arpaci, I., \& Salloum, S. A. (2020). An empirical examination of continuous intention to use m-learning: An integrated model. Education and Information Technologies, 1-20.

Alghizzawi, M., Ghani, M. A., Som, A. P. M., Ahmad, M. F., Amin, A., Bakar, N. A., ... Habes, M. (2018). The Impact of Smartphone Adoption on Marketing Therapeutic Tourist Sites in Jordan. International Journal of Engineering \& Technology, 7(4.34), 91-96. 
Al-Khayyal, A., Alshurideh, M., Al Kurdi, B., \& Aburayya, A. (2020). The impact of electronic service quality dimensions on customers' e-shopping and e-loyalty via the impact of e-satisfaction and e-trust: A qualitative approach. International Journal of Innovation, Creativity and Change, 14(9), 257-281.

Al-Maroof, R. S., Alhumaid, K., Alhamad, A. Q., Aburayya, A., \& Salloum, S. (2021). User acceptance of smart watch for medical purposes: an empirical study. Future Internet, 13(5), 127.

Al-Maroof, R., Ayoubi, K., Alhumaid, K., Aburayya, A., Alshurideh, M., Alfaisal, R., \& Salloum, S. (2021). The acceptance of social media video for knowledge acquisition, sharing and application: A com-parative study among YouTube users and TikTok Users' for medical purposes. International Journal of Data and Network Science, 5(3), 197-214.

Alshurideh, M. (2018). Pharmaceutical Promotion Tools Effect on Physician's Adoption of Medicine Prescribing: Evidence from Jordan. Modern Applied Science, 12(11).

Alshurideh, M. T., Al Kurdi, B., \& Salloum, S. A. (2021). The moderation effect of gender on accepting electronic payment technology: a study on United Arab Emirates consumers. Review of International Business and Strategy.

AlSuwaidi, S. R., Alshurideh, M., Al Kurdi, B., \& Aburayya, A. (2021). The Main Catalysts for Collaborative R\&D Projects in Dubai Industrial Sector. In The International Conference on Artificial Intelligence and Computer Vision (pp. 795-806). Springer.

Balandina, E., Balandin, S., Koucheryavy, Y., \& Mouromtsev, D. (2015). Innovative e-tourism services on top of Geo2Tag LBS platform. In 2015 11th International Conference on Signal-Image Technology \& Internet-Based Systems (SITIS) (pp. 752-759). IEEE.

Baratè, A., Haus, G., Ludovico, L. A., Pagani, E., \& Scarabottolo, N. (2019a). 5G technology and its application to e-learning. In Proceedings of the 11th annual International Conference on Education and New Learning Technologies.

Baratè, A., Haus, G., Ludovico, L. A., Pagani, E., \& Scarabottolo, N. (2019b). 5G TECHNOLOGY FOR MUSIC EDUCATION: A FEASIBILITY STUDY. IADIS International Journal on Computer Science \& Information Systems, 14(1).

Baratè, A., Haus, G., Ludovico, L. A., Pagani, E., Scarabottolo, N., Giovanni, I., \& Antoni, D. (2019). 5G TECHNOLOGY FOR AUGMENTED AND VIRTUAL REALITY IN EDUCATION, 512-516.

Barclay, D., Higgins, C., \& Thompson, R. (1995). The Partial Least Squares (pls) Approach to Casual Modeling: Personal Computer Adoption Ans Use as an Illustration.

Bauer, J. M., \& Bohlin, E. (2018). Roles and effects of access regulation in 5G markets. Available at SSRN 3246177.

Bhardwaj, A. (2020). 5G for Military Communication. Procedia Computer Science, 171(2020), 2665-2674.

Boehm, E. (2019). 5G Is the Future. Reason, 51(6), 20-27. Retrieved from http://search.ebscohost.com.sdl.idm.oclc.org/login.aspx?direct=true $\& d b=a s n \& A N=138630104 \&$ site=eds-live (Accessed: 8 March 2021).

Capuyan, D. L., Capuno, R. G., Suson, R., Malabago, N. K., Ermac, E. A., Demetrio, R. A. M., ... Medio, G. J. (2021). Adaptation of innovative edge banding trimmer for technology instruction: A university case. World Journal on Educational Technology: Current Issues, 13(1), 31-41.

Cheryan, S., Plaut, V. C., Handron, C., \& Hudson, L. (2013). The stereotypical computer scientist: Gendered media representations as a barrier to inclusion for women. Sex Roles, 69(1), 58-71.

Chin, W. W. (1998). The partial least squares approach to structural equation modeling. Modern Methods for Business Research, 295(2), 295-336.

Chuan, C. L., \& Penyelidikan, J. (2006). Sample size estimation using Krejcie and Morgan and Cohen statistical power analysis: A comparison. Jurnal Penyelidikan IPBL, 7, 78-86.

Davis, F. D. (1989). Perceived Usefulness, Perceived Ease of Use, and User Acceptance of Information Technology. MIS Quarterly, 13(3), 319-340. https://doi.org/10.2307/249008

Davis, Fred D, Bagozzi, R. P., \& Warshaw, P. R. (1989). User acceptance of computer technology: a comparison of two theoretical models. Management Science, 35(8), 982-1003.

Davis, Fred D. (1989). Perceived usefulness, perceived ease of use, and user acceptance of information technology. MIS Quarterly, 319-340.

Dijkstra, T. K., \& Henseler, J. (2015). Consistent and asymptotically normal PLS estimators for linear structural equations. Computational Statistics \& Data Analysis, 81, 10-23.

Eid, M. I. M., \& Al-Jabri, I. M. (2016). Social networking, knowledge sharing, and student learning: The case of university students. Computers \& Education, 99, 14-27.

Ellemers, N. (2018). Gender stereotypes. Annual Review of Psychology, 69, 275-298.

Faqih, K. M. S., \& Jaradat, M.-I. R. M. (2015). Assessing the moderating effect of gender differences and individualism-collectivism at individual-level on the adoption of mobile commerce technology: TAM3 perspective. Journal of Retailing and Consumer Services, 22, 37-52.

Fischer, L., Rohm, T., Gnambs, T., \& Carstensen, C. H. (2016). Linking the data of the competence tests. NEPS Survey Paper, 1.

Fornell, C., \& Larcker, D. F. (1981). Evaluating Structural Equation Models With Unobservable Variables and Measurement Error. Journal of Marketing Research, 18(1), 39-50. https://doi.org/10.2307/3151312

Gao, Y. (2021). A Survey Study on the Application of Modern Educational Technology in English Major College Teaching in the Age of 5G Communication. Theory and Practice in Language Studies, 11(2), 202-209.

Gefen, D., \& Straub, D. W. (1997). Gender differences in the perception and use of e-mail: An extension to the technology acceptance model. MIS Quarterly, 389-400.

Gidlund, M., Lennvall, T., \& Åkerberg, J. (2017). Will 5G become yet another wireless technology for industrial automation? In 2017 IEEE International Conference on Industrial Technology (ICIT) (pp. 1319-1324). IEEE.

Gnambs, T. (2021). The development of gender differences in information and communication technology (ICT) literacy in middle adolescence. Computers in Human Behavior, 114, 106533.

Goodhue, D. L., Lewis, W., \& Thompson, R. (2012). Does PLS have adavantages for small sample size or non-normal data? MIS 
Quaterly.

Habes, M., Salloum, S. A., Alghizzawi, M., \& Mhamdi, C. (2020). The Relation Between Social Media and Students' Academic Performance in Jordan: YouTube Perspective. Advances in Intelligent Systems and Computing (Vol. 1058). https://doi.org/10.1007/978-3-030-31129-2_35

Hair Jr, J. F., Hult, G. T. M., Ringle, C., \& Sarstedt, M. (2016). A primer on partial least squares structural equation modeling (PLSSEM). Sage Publications.

Hair, J. F., Ringle, C. M., \& Sarstedt, M. (2011). PLS-SEM: Indeed a silver bullet. Journal of Marketing Theory and Practice, 19(2), $139-152$.

Hair, J., Hollingsworth, C. L., Randolph, A. B., \& Chong, A. Y. L. (2017). An updated and expanded assessment of PLS-SEM in information systems research. Industrial Management \& Data Systems, 117(3), 442-458. https://doi.org/10.1108/IMDS-042016-0130

Hair, J., Hult, G. T. M., Ringle, C., Sarstedt, M., Hair, J. F. F., Hult, G. T. M., ... Sarstedt, M. (2016). A primer on partial least squares structural equation modeling (PLS-SEM). Sage Publications.

Han, M., \& Zhang, X. (2020). Prospects for the advancement of the TikTok in the age of 5G communication. In 2020 13th CMI Conference on Cybersecurity and Privacy (CMI)-Digital Transformation-Potentials and Challenges (51275) (pp. 1-5). IEEE.

Hatlevik, O. E., \& Christophersen, K.-A. (2013). Digital competence at the beginning of upper secondary school: Identifying factors explaining digital inclusion. Computers \& Education, 63, 240-247.

Henseler, J., Dijkstra, T. K., Sarstedt, M., Ringle, C. M., Diamantopoulos, A., Straub, D. W., ... Calantone, R. J. (2014). Common beliefs and reality about PLS: Comments on Rönkkö and Evermann (2013). Organizational Research Methods, 17(2), 182-209.

Henseler, J., Ringle, C. M., \& Sarstedt, M. (2015). A new criterion for assessing discriminant validity in variance-based structural equation modeling. Journal of the Academy of Marketing Science, 43(1), 115-135.

Henseler, J., Ringle, C. M., \& Sinkovics, R. R. (2009). The use of partial least squares path modeling in international marketing. In New challenges to international marketing (pp. 277-319). Emerald Group Publishing Limited.

Hosein, A., Ramanau, R., \& Jones, C. (2010). Learning and living technologies: A longitudinal study of first-year students' frequency and competence in the use of ICT. Learning, Media and Technology, 35(4), 403-418.

Hsu, C.-L., \& Lin, J. C.-C. (2008). Acceptance of blog usage: The roles of technology acceptance, social influence and knowledge sharing motivation. Information \& Management, 45(1), 65-74.

Hu, L., \& Bentler, P. M. (1998). Fit indices in covariance structure modeling: Sensitivity to underparameterized model misspecification. Psychological Methods, 3(4), 424.

Huang, C., Wang, Y., Li, X., Ren, L., Zhao, J., Hu, Y., ... Gu, X. (2020). Clinical features of patients infected with 2019 novel coronavirus in Wuhan, China. The Lancet, 395(10223), 497-506.

Huang, Y. (2014). Empirical analysis on factors impacting mobile learning acceptance in higher engineering education.

Ihme, J. M., \& Senkbeil, M. (2017). Warum können Jugendliche ihre eigenen computerbezogenen Kompetenzen nicht realistisch einschätzen? Zeitschrift Für Entwicklungspsychologie Und Pädagogische Psychologie.

Ilie, V., Van Slyke, C., Green, G., \& Lou, H. (2005). Gender differences in perceptions and use of communication technologies: A diffusion of innovation approach. Information Resources Management Journal (IRMJ), 18(3), 13-31.

Kanaan, R., \& Gharibeh, A. H. (2013). The impact of knowledge sharing enablers on knowledge sharing capability: An empirical study on Jordanian telecommunication firms. European Scientific Journal, ESJ, 9(22).

Kankanhalli, A., Tan, B. C. Y., \& Wei, K.-K. (2005). Contributing knowledge to electronic knowledge repositories: An empirical investigation. MIS Quarterly, 113-143.

Khodabandelou, R., Ab Jalil, H., Wan Ali, W. Z., \& bin Mohd Daud, S. (2014). Moderation Effect of Gender on Relationship between Community of Inquiry and Perceived Learning in Blended Learning Environments. Contemporary Educational Technology, 5(3), 257-271.

Kim, H., Kim, S.-W., Park, E., Kim, J. H., \& Chang, H. (2020). The role of fifth-generation mobile technology in prehospital emergency care: An opportunity to support paramedics. Health Policy and Technology, 9(1), 109-114.

Kline, R. B. (2015). Principles and practice of structural equation modeling. Guilford publications.

Krejcie, R. V, \& Morgan, D. W. (1970). Determining sample size for research activities. Educational and Psychological Measurement, 30(3), 607-610.

$\mathrm{Ku}$, C.-H. (2009). Extending the technology acceptance model using perceived user resources in higher education web-based online learning courses. University of Central Florida.

Lee, J., \& Kim, D. (2020). A study on innovation in university education: focusing on 5G mobile communication. In 2020 IEEE 17th Annual Consumer Communications \& Networking Conference (CCNC) (pp. 1-4). IEEE.

Li, Z. (2021). Simulation of English education translation platform based on web remote embedded platform and 5G network. Microprocessors and Microsystems, 81, 103775.

Liu, Y., Li, H., \& Carlsson, C. (2010). Factors driving the adoption of m-learning: An empirical study. Computers \& Education, $55(3), 1211-1219$.

Lohmöller, J. B. (1989). Latent variable path modeling with partial least squares. Heidelberg, Germany: Physica-Verlag.

Lu, M., Shi, B., Wang, J., Cao, Q., \& Cui, Q. (2010). TAM: a method for enrichment and depletion analysis of a microRNA category in a list of microRNAs. BMC Bioinformatics, 11(1), 1-7.

Mac Callum, K., \& Jeffrey, L. (2014a). Comparing the role of ICT literacy and anxiety in the adoption of mobile learning. Computers in Human Behavior, 39, 8-19.

Mac Callum, K., \& Jeffrey, L. (2014b). Factors impacting teachers' adoption of mobile learning. Journal of Information Technology Education, 13.

Maeng, K., Kim, J., \& Shin, J. (2020). Demand forecasting for the 5G service market considering consumer preference and purchase delay behavior. Telematics and Informatics, 47, 101327. 
Makki, I., Rahmani, N., Aljasmi, M., Mubarak10, S., Salloum11, S. A., \& Alaali, N. (2020). The Impact of the COVID-19 Pandemic on the Mental Health Status of Healthcare Providers in the Primary Health Care Sector in Dubai.

Martin, N., Ragot, M., \& Savaux, V. (2021). Acceptability and 5G in the Medical Field: The Impact of the Level of Information.

Meng, H. (2019). Research on key technologies of intelligent agriculture under 5G environment. In Journal of Physics: Conference Series (Vol. 1345, p. 42057). IOP Publishing.

Minoli, D., \& Occhiogrosso, B. (2019). Practical aspects for the integration of 5G networks and IoT applications in smart cities environments. Wireless Communications and Mobile Computing, 2019.

Moghavvemi, S., Sharabati, M., Paramanathan, T., \& Rahin, N. M. (2017). The impact of perceived enjoyment, perceived reciprocal benefits and knowledge power on students' knowledge sharing through Facebook. The International Journal of Management Education, 15(1), 1-12.

Morris, M. G., \& Venkatesh, V. (2000). Age differences in technology adoption decisions: Implications for a changing work force. Personnel Psychology, 53(2), 375-403.

Mouzaek, E., Al Marzouqi, A., Alaali, N., Salloum, S. A., Aburayya, A., Suson, R. (2021). An Empirical Investigation of the Impact of Service Quality Dimensions on Guests Satisfaction: A Case Study of Dubai Hotels. Journal of Contemporary Issues in Business and Government, 27(3), 1186-1199.

Mtebe, J., \& Raisamo, R. (2014). Investigating students' behavioural intention to adopt and use mobile learning in higher education in East Africa. International Journal of Education and Development Using ICT, 10(3).

Mutono, A., \& Dagada, R. (2016). An investigation of Mobile learning readiness for Post-School Education and Training in South Africa using the Technology Acceptance model. International Journal of Education and Research, 4(9), 353-366.

Neokosmidis, I., Rokkas, T., Parker, M. C., Koczian, G., Walker, S. D., Siddiqui, M. S., \& Escalona, E. (2017). Assessment of sociotechno-economic factors affecting the market adoption and evolution of 5G networks: Evidence from the 5G-PPP CHARISMA project. Telematics and Informatics, 34(5), 572-589.

Nunnally, J. C., \& Bernstein, I. H. (1994). Psychometric theory. McGraw-Hill, New York. https://doi.org/10.1037/018882

Nunnally, Jum C, \& Bernstein, I. H. (1978). Psychometric theory.

Odiakaosa, O. J., \& Jere, N. D. N. (2017). The Usage Pattern of Mobile Devices among High School Teachers in the Oshana and Oshikoto Regions towards the Adoption of Mobile Learning in Namibian High Schools. International Journal of Science and Technology, 1(0), 1.

Park, S. Y. (2009). An analysis of the technology acceptance model in understanding university students' behavioral intention to use e-learning. Journal of Educational Technology \& Society, 12(3), 150.

Peng, R., Lou, Y., Kadoch, M., \& Cheriet, M. (2020). A human-guided machine learning approach for 5G smart tourism IoT. Electronics, 9(6), 947.

Preacher, K. J., \& Hayes, A. F. (2008). Asymptotic and resampling strategies for assessing and comparing indirect effects in multiple mediator models. Behavior Research Methods, 40(3), 879-891.

Rahab, R., \& Wahyuni, P. (2013). Predicting knowledge sharing intention based on theory of reasoned action framework: An empirical study on higher education institution. American International Journal of Contemporary Research, 3(1), 1-10.

Ringle, C. M., Wende, S., \& Becker, J.-M. (2015). SmartPLS 3. Bönningstedt: SmartPLS.

Salloum, S. A., Al-Emran, M., Abdallah, S., \& Shaalan, K. (2017). Analyzing the Arab Gulf Newspapers Using Text Mining Techniques. In International Conference on Advanced Intelligent Systems and Informatics (pp. 396-405). Springer. https://doi.org/10.1007/978-3-319-64861-3 37

Salloum, S.A., Al Ahbabi, N., Habes, M., Aburayya, A., \& Akour, I. (2021). Predicting the intention to use social media sites: A hybrid SME- machine learning approach. In A. Hassanien \& K. Chang (Eds.), Advanced Machine Learning Technologies and Applications, 324-334.

Salloum, S.A., Al-Emran, M., Abdallah, S., \& Shaalan, K. (2018). Analyzing the arab gulf newspapers using text mining techniques. Advances in Intelligent Systems and Computing (Vol. 639). https://doi.org/10.1007/978-3-319-64861-3 37

Salloum, Said A, Alhamad, A. Q. M., Al-Emran, M., Monem, A. A., \& Shaalan, K. (2019). Exploring Students' Acceptance of ELearning Through the Development of a Comprehensive Technology Acceptance Model. IEEE Access, 7, 128445-128462.

Santos-Vijande, M. L., López-Sánchez, J. Á., \& Rudd, J. (2016). Frontline employees' collaboration in industrial service innovation: routes of co-creation's effects on new service performance. Journal of the Academy of Marketing Science, 44(3), 350-375.

Shao, J., Bai, H., Shu, S., \& Joppe, M. (2020). Planners' Perception of Using Virtual Reality Technology in Tourism Planning. EReview of Tourism Research, 17(5).

Tang, Y., Dananjayan, S., Hou, C., Guo, Q., Luo, S., \& He, Y. (2021). A survey on the 5G network and its impact on agriculture: Challenges and opportunities. Computers and Electronics in Agriculture, 180, 105895.

Taryam, M., Alawadhi, D., Aburayya, A., Albaqa'een, A., Alfarsi, A., Makki, I., Rahmani, N., Alshurideh, M., \& Salloum, S. A. (2020). Effectiveness of not quarantining passengers after having a negative COVID-19 PCR test at arrival to dubai airports. Systematic Reviews in Pharmacy, 11(11), 1384-1395. https://doi.org/10.31838/srp.2020.11.197.

Taryam, M., Alawadhi, D., Al Marzouqi, A., Aburayya, A., Albaqa'een, A., Alfarsi, A., Makki, I., Rahmani, N., Aljasmi, M., Mubarak, S., Salloum, S. A., \& Alaali, N. (2021). The impact of the covid-19 pandemic on the mental health status of healthcare providers in the primary health care sector in Dubai. Linguistica Antverpiensia, 21(2), 2995-3015.

Trial, D. (n.d.). Model Fit.

Urbach, N., \& Ahlemann, F. (2010). Structural equation modeling in information systems research using partial least squares. Journal of Information Technology Theory and Application, 11(2), 5-40. https://doi.org/10.1037/0021-9010.90.4.710

Venkatesh, V., Morris, M., Davis, G., \& Davis, F. (2003). User Acceptance of Information Technology: Toward a Unified View. MIS Quarterly, 27(3), 425-478. https://doi.org/10.2307/30036540

Warsame, M. H., \& Ireri, E. M. (2018). Moderation effect on mobile microfinance services in Kenya: An extended UTAUT model. Journal of Behavioral and Experimental Finance, 18, 67-75. 
Xu, X., Li, D., Sun, M., Yang, S., Yu, S., Manogaran, G., .. Mavromoustakis, C. X. (2019). Research on key technologies of smart campus teaching platform based on 5G network. IEEE Access, 7, 20664-20675.

\section{Appendix A}

\section{Instrument development}

Intention to Use 5G (INT)

- INT1: If the $5 \mathrm{G}$ service is available, I have the intention to Use it.

- INT2: I have the intention to Use 5G in my future study.

- INT3: I will Use $5 \mathrm{G}$ in the future to access services and applications.

\section{Perceived Skills Readiness (PSR)}

- PSR1: I am skillful enough to Use 5G in learning.

- PSR2: I can Use my Skills to download any material via 5G.

- $\quad$ PSR3: I am skillful enough to Use different applications and services using 5G.

\section{Perceived Ease of Use (PEOU)}

- PEOU1: I think it is easy to Use 5G.

- PEOU2: I think it is easy to Use 5G for educational purposes.

- PEOU3: G5 will not caUse any difficulty in usage.

\section{Perceived Usefulness (PU)}

- PU1: Using 5G will be useful in my personal education.

- PU2: Using 5G will be useful to download applications and Services.

- PU3: Using 5G will be useful in enhancing my educational skills.

\section{Perceived Enjoyment (PEN)}

- PEN1: I think that using 5G is enjoyable for educational purposes.

- PEN2: I think that using 5G is fun to access different educational sites.

- PEN3: I think that using 5G is interesting to download educational material.

\section{Perceived Resources (PR)}

- PR1: I think the 5G infrastructure supports educational applications.

- PR2: I think that the 5G infrastructure is helpful for future educational purposes.

- PR3: I think 5G infrastructure can enhance my educational process.

\section{Gender Differences (GD)}

- GENDER1: There is a difference between male and female students in using 5G for educational purposes.

- GENDER2: There is a difference between male and female students in Ease of using 5G.

- GENDER3: There is a difference between male and female students in Usefulness using 5G.

- GENDER4: There is a difference between male and female students in the Perceived Enjoyment in using 5G.

- GENDER5: There is a difference between male and female students in rusting the source of internet (infrastructure).

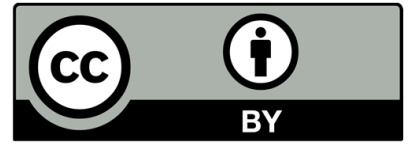

(C) 2021 by the authors; licensee Growing Science, Canada. This is an open access article distributed under the terms and conditions of the Creative Commons Attribution (CC-BY) license (http://creativecommons.org/licenses/by/4.0/). 